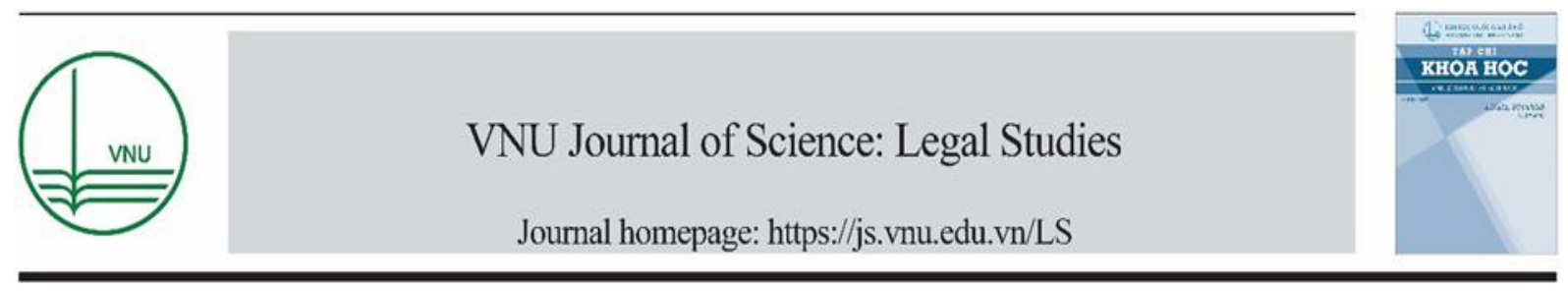

Review Article

\title{
Transparency and Evaluation of Transparency in the Adjudication and Exercise of the Judicial Power of the Court in Vietnam
}

\author{
Nguyen Ngoc Chi ${ }^{*}$ \\ VNU School of Law, 144 Xuan Thuy, Cau Giay, Hanoi, Vietnam \\ Received 15 March 2021 \\ Revised 20 March 2021; Accepted 26 March 2021
}

\begin{abstract}
Recent studies have shown that alongside the implementation of transparency, the evaluation of transparency in the adjudication and exercise of the judicial power of the court is an objective requirement for a rule-of-law country. However, each form of organization of judicial power and each design of the court system have a different approach to the evaluation of the transparency in the adjudication and exercise of the judicial power. Therefore, aside from the common ground that is acknowledging the importance of the evaluation of transparency in the adjudication and exercise of the judicial power, the purpose, mechanism, method, and criteria for evaluation vary in accordance to each country, each historical period. The judicial reform in Vietnam requires for evaluation of transparency in the adjudication and exercise of the judicial power of the court. Initial steps have been made to perform evaluation to a certain extent, however this has proven insufficient for the goal to "build a clean, strong, just, democratic, and step-by-step modernized judicial system to serve the people, to serve the Socialist Republic of Vietnam". For this reason, this paper aims to clarify the theoretical and practical foundation of transparency and evaluation of transparency in the adjudication and exercise of the judicial power in Vietnam under the human rights-based approach, the dialectical materialism approach, and scientific research methods, among which the comparative law method is emphasized.
\end{abstract}

Keywords: Judicial transparency; open and transparent justice; adjudication and exercise of judicial power; court; evaluation mechanism for transparency.

\footnotetext{
${ }^{*}$ Corresponding author.

E-mail address: chinn1957@
}

https://doi.org/10.25073/2588-1167/vnuls.4351 


\title{
Minh bạch và đánh giá tính minh bạch trong hoạt động xét xử, thực hiện quyền tư pháp của tòa án ở Việt Nam
}

\author{
Nguyễn Ngọc Chí \\ Khoa Luật, Đại học Quốc gia Hà Nội, 144 Xuân Thủy, Cầu Giấy, Hà Nội, Việt Nam \\ Nhận ngày 15 tháng 3 năm 2021 \\ Chỉnh sửa ngày 20 tháng 3 năm 2021; Chấp nhận đăng ngày 26 tháng 5 năm 2021
}

\begin{abstract}
Tóm tắt: Các nghiên cứu gần đây đã chỉ ra cùng với sự thể hiện công khai, minh bạch thì đánh giá tính công khai, minh bạch trong hoạt động xét xử, thực hiện quyền tư pháp của tòa án là đòi hỏi khách quan trong nhà nước pháp quyền. Tuy nhiên, mồi hình thức tổ chức thực hiện quyền tư pháp và mỗi phương thức thiết kế bộ máy tòa án lại có cách thức đánh giá tính công khai, minh bạch trong hoạt động xét xử, thực hiện quyền tư pháp khác nhau nên bên cạnh việc khẳng định tính tất yếu của hoạt động đánh giá tính công khai, minh bạch trong hoạt động xét xử, thực hiện quyền tư pháp thì mục đích, cơ chế, cách thức, tiêu chí đánh giá ở mỗi nhà nước, mỗi giai đoạn lịch sử lại có sự khác nhau. Ở Việt Nam, trong quá trình cải cách tư pháp đã đặt ra vấn đề đánh giá tính công khai, minh bạch trong hoạt động xét xử, thực hiện quyền tư pháp của tòa án và bước đầu có các hoạt động đánh giá ở những phạm vi nhất định nhưng chưa đáp ứng được định hướng "xây dựng nền tư pháp trong sạch, vững mạnh, dân chủ, nghiêm minh, bảo vệ công lý, từng bước hiện đại, phục vụ nhân dân, phụng sự Tổ quốc Việt Nam xã hội chủ nghĩa" [1]. Do đó, bài viết này hướng tới việc làm rõ cơ sở lý luận và thực tiễn về minh bạch và đánh giá tính minh bạch trong hoạt động xét xử, thực hiện quyền tư pháp ở Việt Nam trên cơ sở phương pháp tiếp cận quyền, phương pháp tiếp cận của chủ nghĩa duy vật biện chứng và các phương pháp nghiên cứu khoa học, trong đó nhấn mạnh đến phương pháp luật học so sánh.
\end{abstract}

Tù khóa: Minh bạch tư pháp; công khai, minh bạch tư pháp; xét xử, thực hiện quyền tư pháp; tòa án; cơ chế đánh giá tính công khai, minh bạch.

\section{Công khai, minh bạch trong hoạt động xét xử, thực hiện quyền tư pháp của tòa án}

i) Minh bạch là một trong các thuộc tính làm nên bản chất tiến bộ của nền tư pháp văn minh; thuộc tính này không những bảo đảm khách quan, công bằng trong quá trình giải quyết vụ án mà còn tạo điều kiện để xã hội, người dân thực hiện quyền giám sát hoạt động tư pháp, thông qua đó góp phần bảo đảm công lý, bảo đảm quyền con người. Theo tiếp cận của

\footnotetext{
*Tác giả liên hệ.

Địa chỉemail: xc77vttl@gmail.com

https://doi.org/10.25073/2588-1167/vnuls.4293
}

Liên Hợp quốc: "Minh bạch xét xử là một giá trị quan trọng thường được nói gọn là "không những công lý phải được thực thi, mà công lý phải được nhìn thấy là đã được thực thi”. Minh bạch xét xử cũng được công nhận là một nguyên tắc quan trọng trong các tài liệu nhân quyền quốc tế, trong đó xác định quyền được xét xử công khai và thông báo công khai về bản án là một trong những nền tảng của quyền được xét xử công bằng" [2]. Tại phương Tây, các nghiên cứu được phát triển hàng trăm năm qua đã hỗ trợ đắc lực trong hoạt động và cải thiện hiệu quả hoạt động của tòa án cũng như tính minh bạch trong hoạt động của cơ quan này thông qua việc thiết kế hệ thống, đến giám sát 
của quần chúng, sự đánh giá, đo lường bởi các định chế độc lập.

Ngay từ thời kỳ cổ đại các nhà tư tưởng như: Plato và Aristotle, Cicero đã quan tâm tới quyền tư pháp dưới những nghiên cứu về nhà nước, phân quyền giữa lập pháp, hành pháp và tư pháp, về thi hành pháp luật, nhưng còn sơ khai. Thời kỳ tiền trung cổ Augustinus, Thomas von Aquin và Marsilius von Padua đã quan tâm nghiên cứu về tổ chức thực hiện quyền lực nhà nước, các tác giả cho rằng trong nhà nước tồn tại các nhánh quyền lực và các nhánh quyền này cần được tách bạch. Thời kỳ Trung cổ có các đại diện như: J.Bodin, Th.Hobbes và V.L.von Seckendorff, thời cận đại (đến khoảng năm 1900) có các đại diện như: John Locke, Montesquieu, ... Đây là thời kỳ có những cuộc luận chiến về tổ chức quyền lực nhà nước, nhiều tác giả cho rằng để hạn chế quyền lực, chống độc quyền nên cần áp dụng nguyên tắc phân quyền giữa các quyền lập pháp, hành pháp và tư pháp. Trong trào lưu chính thống của triết học Đức về vấn đề nhà nước, tư pháp phải kể đến I. Kant, G. W. F. Hegel và K. Marx,... Các công trình thể hiện tư tưởng phân quyền trong việc tổ chức thực hiện quyền lực nhà nước, cũng như thiết kế bộ máy công quyền, về thực thi và chấp hành pháp luật được đề cập khá nhiều, nhưng việc khảo cứu sâu về tư pháp, tòa án, đặc biệt là đặc tính minh bạch và hiệu quả hoạt động của tòa án chỉ mới được quan tâm nhiều hơn vào cuối thế kỷ XIX, đầu thế kỷ XX.

Đến cuối thập niên 70 của thế kỷ XX, các phương pháp đánh giá về hiệu quả và tác động của chính sách pháp luật ở các nước phương Tây đã được xem như là phương pháp phân tích trong lĩnh vực chính trị - hành chính và tư pháp. Do áp lực phải siết chặt chi tiêu ngân sách do ảnh hưởng của cuộc khủng hoảng dầu lửa vào năm 1973 và những phê phán của nhóm tự do mới đối với việc mở rộng nhà nước phúc lợi nên đã xuất hiện những nghiên cứu về việc xem xét, kiểm soát chi phí dành cho các chương trình chính sách và hướng tới đánh giá "đầu vào - hiệu quả" hơn là "đầu ra - hiệu lực". Tiêu biểu cho khuynh hướng này, có thể kể đến các ấn phẩm: Impoving Productivity and Productivity Measurement in Local Government (Nâng cao hiệu quả và đo lường hiệu quả trong khu vực công ở địa phương) của H. Harty, D. Fish [3]; Productivity in the Local Government Sector (Hiệu quả trong khu vực công ở địa phương) của $\mathrm{J}$. Ross Burkhead [4]. Các vấn đề về minh bạch và hiệu quả gắn với những tìm kiếm và xây dựng các nguyên tắc quản lý nhằm nâng cao chất lượng, đo lường hiệu suất làm việc của các thiết chế công được đặc biệt chú trọng trong các nghiên cứu. Những công trình này đã đề xuất đến sự cần thiết của việc đo lường hiệu quả hoạt động của các cơ quan hành chính và tư pháp. Các nghiên cứu tập trung vào nhiệm vụ bổ sung các thiếu hụt về thông tin liên quan đến đánh giá hiệu quả hoạt động của tổ chức hành chính - tư pháp bằng việc phân tích tiến trình và hiệu quả của quá trình đánh giá, cũng như các tác động mang tính kinh tế - xã hội của các chương trình quốc gia. Nghiên cứu hiệu quả của hoạt động hành chính - tư pháp trong giai đoạn này không chỉ nhằm mục đích nâng cao chất lượng quản lý hay nhằm kiểm soát chi phí, mà quan trọng hơn là đưa ra chính sách sử dụng các nguồn lực hiệu quả hơn.

Một điểm cần nhấn mạnh là từ những thập niên giữa thế kỷ XX, nhờ sự hỗ trợ của Liên Hợp Quốc, các hội nghị quốc tế tập hợp các chuyên gia về hoạt động quản lý nhà nước thường xuyên được tổ chức. Trong khuôn khổ các chương trình phát triển của Liên Hợp Quốc, nhiều công trình, đề tài nghiên cứu khoa học lớn về liêm chính tư pháp nói chung và đánh giá tính công khai, minh bạch hoạt động của tòa án nói riêng được thực hiện. Cùng với đó là các nghiên cứu so sánh về phương pháp đánh giá và thành tựu của các nước về tính công khai, minh bạch của tòa án. Trong giai đoạn này, nhiều công trình nghiên cứu đã bổ sung và hoàn thiện lý thuyết về hiệu quả và tiếp cận nghiên cứu các phương pháp quản lý trong khu vực tư để áp dụng và khu vực công, trong đó có đề cập đến tính minh bạch tư pháp. Ở lĩnh vực nghiên cứu này có thể kể đến một số công trình nghiên cứu như: Productivity Impovement Technique (Kỹ thuật nâng cao hiệu quả) do J. Matzer Chủ biên [5]; Partitioners Guide to Public Sector Productivity improvement (Cẩm nang hướng dẫn cho nhà hoạt động thực tiễn trong nâng cao 
hiệu quả quản lý ở khu vực công) của E.A. Morley [6]; Evaluation and Effective Public Management (Đánh giá về hiệu quả của quản lý công) của J. F. Wholey [7].

Nghiên cứu so sánh tương đồng sẽ là một bổ sung quan trọng trong quá trình áp dụng kinh nghiệm quốc tế vào các vấn đề quốc gia. Đối với Việt Nam gần đây, có lẽ mô hình Đông Á nhận được nhiều sự quan tâm của cả giới kỹ trị và khoa học. Bởi lẽ, các quốc gia tại đây vừa có tương đồng về văn hóa với Việt Nam, song lại rất phát triển về kinh tế và các thiết chế xã hội, đặc biệt là Nhật Bản, Hàn Quốc và Trung Quốc. Tòa án với vai trò là trung tâm của hệ thống tư pháp, có tác động mạnh mẽ đến toàn bộ đời sống chính trị - xã hội của quốc gia. Do đó, mối quan tâm nghiên cứu về tòa án trải rộng ra nhiều phạm vi, từ mối quan hệ của tòa án với các thiết chế quyền lực khác, đến vai trò của tòa án trong việc tiếp cận công lý của người dân, tính liêm chính của tòa án trong hoạt động xét xử.

Giáo sư Kin Sung-ho (Đại học Yonsei), trong bài The Constitutional Soul of Korea's democracy (Linh hồn hiến pháp của nền dân chủ Hàn Quốc) [8] đã phân tích về vai trò ngày càng gia tăng của Tòa án Hiến pháp và sự xung đột của chủ nghĩa lập hiến với dân chủ như là kết quả của khuynh hướng “tư pháp hóa chính trị" (judicialization of politics). Cạnh đó, TS. Cha Dong-wook, trong bài viết The Constitutional Court: Political or Legal (Tòa án Hiến pháp: chính trị và pháp lý) [9] sau khi phân tích thực tiễn xét xử của tòa án, bao gồm hai vụ việc nổi bật vào năm 2004 (luận tội tổng thống và di dời thủ đô) đi đến kết luận rằng mặc dù chính trị bao trùm hầu hết mọi khía cạnh của Tòa án Hiến pháp - phương thức lựa chọn các thẩm phán, các cá nhân và cơ quan có thể tiếp cận tòa án, các vụ việc mà tòa án đã xét xử và các phản ứng đối với một phán quyết. Tuy vậy, Tòa án Hiến pháp phải thuyết phục xã hội rằng các phán quyết của mình không dựa trên các cân nhắc chính trị đảng phái thiên lệch mà dựa trên luật pháp trung lập, khách quan, ngay cả khi các vấn đề rõ ràng là gây tranh cãi về nguồn gốc hoặc hậu quả chính trị. Tòa án cần phải chuyển cách tranh cãi về chính sách công thành các vấn đề giải thích hiến pháp mà được quyết định bằng các văn bản, thủ tục, nguyên tắc mà được đa số coi là luật chứ không phải là chính trị.

Nghiên cứu so sánh tại các quốc gia Đông Á ngày càng nhận được sự quan tâm lớn hơn của các học giả trong khu vực cũng như trên thế giới. Tương đối nổi bật trong khu vực là Giáo sư Wen-chen Chang, tại Đại học Quốc gia Đài Loan, người có nhiều nghiên cứu so sánh về sự tiến triển của các chủ nghĩa lập hiến và ưu điểm của mô hình tư pháp ở Đông Á trong vai trò là một đối trọng quyền lực. Bà có một số nghiên cứu đăng tạp chí như East Asian Foundation for Constitutionalism: Three Models Reconstructed (Nền tảng Đông Á cho chủ nghĩa hợp hiến: tái thiết ba mô hình) [10]; The Emergence of East Asian Constitutionalism: Features in Comparison (Sự nổi lên của chủ nghĩa lập hiến Đông Á: so sánh các đặc điểm) [11, tr.805], viết chung với GS. Jiunn-Rong Yeh cùng ở Đại học Đài Loan; Strategic judicial responses in politically charged cases: East Asian experiences (Phản ứng mang tính chiến lược của cơ quan tư pháp đối với các vụ án hình sự về chính trị: kinh nghiệm Đông Á) [12], so sánh chủ yếu kinh nghiệm của Đài Loan và Hàn Quốc khi xét xử các chính trị gia cao cấp,...

ii) Các nghiên cứu về minh bạch tư pháp, tuy còn có khác biệt nhưng đều chỉ ra những đặc điểm chung sau đây:

Thứ nhất, minh bạch tư pháp là tất yếu trong nhà nước nước pháp quyền. Nhà nước pháp quyền đòi hỏi mọi quyền lực nhà nước đều thuộc về nhân dân và việc thực hiện quyền lực nhà nước phải công khai, minh bạch và có sự tham gia của dân trên cơ sở trách hiệm giải trình của các cơ quan nhà nước. Các nghiên cứu ở Việt Nam đưa ra lập luận về sự tất yếu, đòi hỏi của nhà nước pháp quyền XHCN đối với minh bạch tư pháp như sau: "Quyền lực chính trị, quyền lực nhà nước là công khai, hợp pháp. Quyền tư pháp với tư cách là một trong ba bộ phận, phạm vi, lĩnh vực, loại quyền lực nhà nước, tất yếu, là công khai, hợp pháp. Chế độ tư pháp là công khai, vì xét trên tất cả các phương diện, chế độ tư pháp ghi nhận, thể hiện việc tổ 
chức và thực hiện quyền tư pháp, do vậy, là công khai, hợp pháp.”[13] Tư pháp là một trong những nhánh quyền lực nhà nước, do đó, xét xử - hoạt động quan trọng nhất của tòa án cần phải được minh bạch, đó là thẩm quyền được trao cho tòa án và các thẩm phán xem xét và quyết định các vụ việc và đưa ra phán quyết có giá trị bắt buộc thi hành đối với các vụ việc ấy; quyền giải thích và áp dụng pháp luật khi có tranh cãi phát sinh từ việc một điều gì đó có phù hợp hay không phù hợp với pháp luật điều chỉnh việc ấy [14, tr.924]. Theo tài liệu Hướng dẫn tăng cường năng lực và liên chính Tư pháp của Liên hợp quốc thì: "Minh bạch xét xử là một giá trị quan trọng thường được nói gọn là không những công lý phải được thực thi, mà công lý phải được nhìn thấy là đã được thực thi" [15]. Minh bạch xét xử cũng được công nhận là một nguyên tắc quan trọng trong các tài liệu nhân quyền quốc tế, trong đó xác định quyền được xét xử công khai và thông báo công khai về bản án là một trong những nền tảng của quyền được xét xử công bằng [16]. Đồng thời, minh bạch tư pháp còn đòi hỏi "sự tiếp cận hiệu quả với thông tin như những cách thức để củng cố sự tham gia của người dân" [20; tr.85]. Như vậy, minh bạch tư pháp là đòi hỏi tất yếu khách quan trong nhà nước pháp quyền, là một bảo đảm quyền con người và có ý nghĩa to lớn trong đời sống xã hội.

Thứ hai, minh bạch tư pháp có phạm vi rộng với các nội hàm sau: a) Minh bạch tư pháp không chỉ là sự rõ ràng của các quy định pháp luật mà còn bao gồm cả sự công khai kết quả hoạt động xét xử của tòa án và việc tiếp cận thông tin đối với tất cả các vấn đề về tổ chức, nhân sự, các điều kiện hoạt động liên quan đến xét xử; b) Minh bạch trong việc xây dựng, ban hành pháp luật, bảo đảm hệ thống pháp luật nhất là luật tố tụng phải phù hợp với các tiều chí quốc tế về quyền con người và các chuẩn mực tố tụng mang tính phổ quát của nhân loại; c) Hoạt động xét xử của tòa án phải được minh bạch, bảo đảm việc xét xử được công khai trừ một số trường hợp đặc biệt; d) Người dân và giới truyền thông phải tiếp cận được với các tài liệu, hồ sơ và bản án của tòa án. "Để minh bạch, tòa án phải đảm bảo rằng người dân và giới truyền thông có thể tham dự phiên tòa, nhưng quan trọng không kém là phải luôn sẵn sàng để người dân tiếp cận với các tài liệu của tòa án, nhất là bản án và những quyết định khác, cũng như các thông tin hành chính liên quan đến tòa án" [2, tr.85]; e) Minh bạch tư pháp gắn liền với trách nhiệm giải trình tư pháp. Trong tư pháp, trách nhiệm giải trình thuộc về tòa án, cơ quan đã nhận quyền lực từ nhân dân và đặt ra mục tiêu thực thi quyền lực vì nhân dân thì đồng thời có nghĩa vụ trả lời, lý giải và chịu trách nhiệm đối với hoạt động xét xử của mình. Do đó, minh bạch tư pháp gắn liền với trách nhiệm giải trình, tòa án có trách nhiệm cung cấp, giải thích, làm rõ các thông tin về quyết định, bản án và các vấn đề khác có liên quan đến việc thực hiện chức năng xét xử và thực hiện quyền tư pháp của mình.

Thứ ba, phạm vi của minh bạch tư pháp. Các nghiên cứu ở Việt Nam quan niệm minh bach tư pháp theo nghĩa hẹp và tách bạch thành hai khái niệm "công khai", "minh bạch" khác với "Minh bạch" theo quan niệm chung của thế giới, khi đề cập đến minh bạch đã bao gồm cả công khai. Sự khác nhau này không ảnh hưởng nhiều đến bản chất của minh bạch tư pháp mà chỉ mang tính kỹ thuật khi nghiển cứu phạm trù này. Theo đó: a) "Tính công khai của chế độ tư pháp bảo đảm để mọi người có thể biết đến, hiểu được, giám sát được quyền tư pháp và việc thực hiện quyền tư pháp, đồng thời nâng cao tinh thần trách nhiệm của các chủ thể quyền tư pháp và thực hiện quyền tư pháp và các chủ thể tham gia thực hiện quyền tư pháp"; và bao gồm công khai về chế độ pháp luật về tư pháp; công khai về tổ chức thực hiện quyền tư pháp - tổ chức của Toà án; công khai về hoạt động thực hiện quyền tư pháp - hoạt động của Toà án; công khai về kết quả hoạt động thực hiện quyền tư pháp - kết quả hoạt động của Toà án; công khai về Thẩm phán" [13]; b) "Tính minh bạch của chế độ tư pháp có nghĩa là tính rõ ràng, rành mạch, tính hiểu được của chế độ tư pháp. Tính minh bạch của chế độ tư pháp được thể hiện ở sự minh bạch của các quy định pháp luật thuộc chế độ pháp luật về tư pháp, tính minh bạch trong hoạt động của Toà án, tính rõ ràng, 
tính hiểu được của/về các phán quyết của Toà án” [13].

\section{2. Đánh giá tính công khai, minh bạch trong hoạt động xét xử, thực hiện quyền tư pháp của tòa án}

Nếu như công khai, minh bạch là quy luật tất yếu đối với hoạt động xét xử, thực hiện quyền tư pháp của tòa án trong nhà nước pháp quyền thì việc đánh giá mức độ đạt được tính công khai, minh bạch thì việc đánh giá nó so với mục tiêu đặt ra cũng là đòi hỏi khách quan, do yêu cầu của việc kiểm soát thực hiện quyền lực tư pháp thông qua hoạt động xét xử của toà án. Nếu như tính minh bạch trong hoạt động xét xử vụ án hình sự đã được thể hiện trong hệ thống pháp luật thì sẽ đòi hỏi sự kiểm tra, đánh giá mức độ minh bạch được thể hiện như thế nào trong thực tiễn xét xử, đồng thời thông qua đó cũng đánh giá được mức độ thỏa mãn các yêu cầu về tính minh bạch trong hoạt động xét xử của xã hội đối với hệ thống pháp luật.

Ở mỗi mô hình tổ chức thực hiện quyền tư pháp và mỗi phương thức thiết kế Bộ máy tòa án lại có cách thức đánh giá tính công khai, minh bạch trong hoạt động xét xử, thực hiện quyền tư pháp khác nhau nên bên cạnh việc khẳng định tính yếu của hoạt động đánh giá tính công khai, minh bạch trong hoạt động xét xử, thực hiện quyền tư pháp thì mục đích, cơ chế, cách thức, tiêu chí đánh giá ở mỗi nhà nước, mỗi giai đoạn lịch sử lại có sự khác nhau.

Trong khuôn khổ các Chương trình phát triển của Liên Hợp quốc, nhiều công trình, đề tài nghiên cứu khoa học lớn về liêm chính tư pháp đã khẳng định việc đánh giá tính công khai, minh bạch và trách nhiệm giải trình của các cơ quan tư pháp được coi trọng trong xu thế cải cách hiện nay và coi đó là một trong những nền tảng của quyền được xét xử công bằng [2].

Việc đánh giá tính minh bạch trong hoạt động xét xử vụ án hình sự cần phải được tiến hành trên hai phương diện, đó là mức độ minh bạch được thể hiện trong các hệ thống pháp luật TTHS và mức độ đạt được về tính minh bạch trong thực tiễn hoạt động xét xử của tòa án.
Trên cả hai phương diện này, khi tiến hành đánh giá cần phải dựa trên các căn cứ, tiêu chí nhất định làm cơ sở và lập luận cho việc đánh giá. Nói cách khác, việc đánh giá tính minh bạch trong hoạt động xét xử vụ án hình sự cần phải được tiến hành trên hai phương diện, đó là mức độ minh bạch được thể hiện trong các hệ thống pháp luật TTHS và mức độ đạt được về tính minh bạch trong thực tiễn hoạt động xét xử của tòa án.

\section{Cơ chế đánh giá và cách tiếp cận đối với việc đánh giá tính công khai, minh bạch trong hoạt động xét xử, thực hiện quyền tư pháp của tòa án}

\subsection{Khái niệm cơ chế đánh giá tính công khai, minh bach trong hoạt động xét xủ, thực hiện quyền tu pháp của tòa án}

Cho đến nay chưa có khái niệm cơ chế đánh giá tính công khai, minh bạch trong hoạt động xét xử, thực hiện quyền tư pháp của tòa án được đưa ra, tuy nhiên, theo ngữ nghĩa của các từ điển thì có thể hiểu "cơ chế đánh giá tính công khai, minh bạch trong hoạt động xét xử, thực hiện quyền tư pháp của tòa án là sự vận hành của các bộ phận trong hoạt động đánh giá tính công khai, minh bạch trong hoạt động xét xử, thực hiện quyền tư pháp của tòa án tại thời điểm nhất định theo quy định của pháp luật và quy trình được ấn định nhằm xác định mức độ minh bạch được thể hiện trong các hệ thống pháp luật TTHS và mức độ đạt được về tính minh bạch trong thực tiễn hoạt động xét xử của tòa án”. Khái niệm này phù hợp với các nghiên cứu gần đây, nhất là của Liên hợp quốc và đã chỉ ra các nội hàm của cơ chế đánh giá tính công khai, minh bạch trong hoạt động xét xử, thực hiện quyền tư pháp của tòa án, theo đó, sẽ bao gồm:

Thứ nhất, chủ thể đánh giá tính công khai, minh bạch trong hoạt động xét xử, thực hiện quyền tư pháp của tòa án.

Việc đánh giá tính công khai, minh bạch trong hoạt động xét xử, thực hiện quyền tư pháp của tòa án, ở mức độ khái quát nhất có thể 
khẳng định bất kỳ ai, cơ quan, tổ chức nào cũng có thể tiến hành với những mục đích khác nhau. Tuy nhiên, theo quy định của pháp luật thì chỉ những chủ thể nhất định mới có trách nhiệm, nghĩa vụ đánh giá tính công khai, minh bạch trong hoạt động xét xử, thực hiện quyền tư pháp của tòa án và theo cách phân loại thông thường sẽ có đánh giá trong và đánh giá ngoài, mà mỗi loại đánh giá này sẽ có các chủ thể tương ứng. Theo đó, tòa án là chủ thể đánh giá tính công khai, minh bạch trong hoạt động xét xử, thực hiện quyền tư pháp (đánh giá trong), trước hết phải do từng tòa án và tòa án cấp trên tiến hành nhằm xác định mức độ công khai, minh bạch đối với các hoạt động của mình thông qua việc kiểm tra, thanh tra, giám đốc xét xử, kháng nghị...theo quy định của pháp luật. Các cơ quan, tổ chức, cá nhân bên ngoài hệ thống tòa án là chủ thể đánh giá tính công khai, minh bạch trong hoạt động xét xử, thực hiện quyền tư pháp của tòa án (đánh giá ngoài) trên cơ sở quy định của pháp luật.

Thứ hai, việc đánh giá tính công khai, minh bạch trong hoạt động xét xử, thực hiện quyền tư pháp của tòa án phải được luật hóa.

Là một bộ phận của tính công khai, minh bạch trong hoạt động xét xử, thực hiện quyền tư pháp của tòa án thì việc đánh giá tính công khai, minh bạch trong hoạt động xét xử, thực hiện quyền tư pháp của tòa án cũng cần phải được quy phạm hóa, buộc các chủ thể liên quan phải thực hiện. Nếu như tính minh bạch trong hoạt động xét xử vụ án hình sự đã được thể hiện trong hệ thống pháp luật thì sẽ đòi hỏi sự kiểm tra, đánh giá mức độ minh bạch được thể hiện như thế nào trong thực tiễn xét xử, đồng thời thông qua đó cũng đánh giá được mức độ thỏa mãn các yêu cầu về tính minh bạch trong hoạt động xét xử của xã hội đối với hệ thống pháp luật. Như vậy, trên cả hai phương diện, đó là mức độ công khai, minh bạch được thể hiện trong các hệ thống pháp luật tố tụng và mức độ đạt được về tính công khai, minh bạch trong thực tiễn hoạt động xét xử của tòa án đều phải được pháp luật quy định. Pháp luật về đánh giá tính công khai, minh bạch trong thực tiễn hoạt động xét xử của tòa án điều chỉnh phạm vi, giới hạn quyền, nghĩa vụ của các chủ thể cũng như cách tiếp cận và phương thức đánh giá...làm cơ sở cho các hoạt động đánh giá tính công khai, minh bạch trong thực tiễn hoạt động xét xử của tòa án là một trong những nền tảng của quyền được xét xử công bằng [2, tr.85].

Thứ ba, hình thành quy trình đánh giá tính công khai, minh bạch trong hoạt động xét xử, thực hiện quyền tư pháp của tòa án.

Việc đánh giá đòi hỏi khách quan, phản ánh trung thực mức độ công khai, minh bạch trong xét xử, thực hiện quyền tư pháp của tòa án nên cần có quy trình đánh khoa học với mục tiêu phù hợp, căn cứ, tiêu chí đánh giá cụ thể, rõ ràng và các điều kiện đánh giá phải bảo đảm. "Do vậy, việc đánh giá hoạt động phải được thực hiện không chỉ về phương diện pháp lý và quản lý mà còn phải thông qua việc tạo ra các kênh để lắng nghe tiếng nói từ những đối tượng tham gia tố tụng tại tòa án và những kỳ vọng chung của công chúng." $[2$, tr.102] Quy trình đánh giá tính công khai, minh bạch trong hoạt động xét xử, thực hiện quyền tư pháp của tòa án bao gồm những bước sau đây: i) Xác định mục tiêu của việc đánh giá tính công khai, minh bạch trong hoạt động xét xử, thực hiện quyền tư pháp của tòa án là quan trọng, có ý nghĩa định hướng cho hoạt động đánh giá. Mục tiêu phải rõ ràng, cụ thể, nêu rõ thời hạn và ý nghĩa của việc đánh giá; ii) Xây dựng các chỉ số đánh giá tính công khai, minh bạch trong hoạt động xét xử, thực hiện quyền tư pháp của tòa án cần cụ thể, có thể so sánh được các chỉ số định tính và định lượng. Hình thành một bộ các biến số để đánh giá những thay đổi đối với minh bạch tư pháp trong khoảng thời gian nhất định; iii) Thu thập nguồn dữ liệu, lựa chọn các phương pháp và kỹ thuật đánh giá: Việc xây dựng các chỉ số đánh giá phải được xây dựng trên cơ sở tính đến các dữ liệu thông tin có sẵn, các dữ liệu có thể thu thập được và chi phí của việc thu thập và phân tích dữ liệu thông tin tiết giảm đến mức thấp nhất có thể. Với cách tiếp cận này thì nguồn dữ liệu thu thập cần hướng tới những dữ liệu sẵn có để giảm thiểu tối đa chi phí, đồng thời phải lựa chọn các phương pháp và biện pháp kỹ thuật hiệu quả, khách quan, phù hợp. Trong mọi trường hợp, dữ liệu thu thập được phải chuyển thành thông tin và kiến thức có thể góp phần 
nâng cao hiệu quả việc thực hiện chức năng của tòa án. Chất lượng dữ liệu phải luôn luôn được kiểm chứng dù đó là dữ liệu được thu thập từ sổ ghi án bằng giấy, hay đối với các dữ liệu thu thập được từ các hệ thống quản lý án điện tử. Cần có những nỗ lực để đảm bảo rằng việc nhập dữ liệu được đồng bộ, thống nhất ở mức cao nhất nhằm tránh làm cho việc so sánh giữa các tòa án bị sai lệch khi thu thập thông tin bằng các tiêu chí khác nhau. Trong nỗ lực này việc xây dựng một cuốn từ điển dữ liệu cũng như sự tham gia của các cơ quan thanh tra trong việc kiểm soát chất lượng dữ liệu là cần thiết $[2$, tr.102].

3.2. Cách tiếp cận khi đánh giá tính công khai, minh bach trong hoạt động xét xư, thực hiện quyền tu pháp của tòa án

Khi đánh giá tính công khai, minh bạch trong hoạt động xét xử, thực hiện quyền tư pháp của tòa án cần phải lựa chọn cách tiếp cận phù hợp với thực tiễn và mục tiêu đánh giá đã xác định. Theo các nghiên cứu của Liên hợp quốc những năm gần đây thì việc đánh giá tính công khai, minh bạch trong hoạt động xét xử, thực hiện quyền tư pháp của tòa án có các cách tiếp cận sau:

- Tiếp cận toàn diện: Liên Hợp quốc, Hướng dẫn tăng cường năng lực và liêm chính tư pháp của Liên hợp quốc đã chỉ ra: "Một sự đánh giá mang tính toàn diện đối với các hệ thống tư pháp đang trở thành một thách thức có tính chiên lược đối với các nền tư pháp trên toàn thế giới." Cách tiếp cận này, đòi hỏi không chỉ đánh giá tính công khai, minh bạch trong hoạt động xét xử, thực hiện quyền tư pháp của tòa án mà còn phải đánh giá những gì được coi là hoạt động pháp lý của một tòa án và về các chủ thể có liên quan đến hoạt động xét xử (thẩm phán, thư ký,...) [2].

- Tiếp cận thường xuyên: Việc đánh giá tính công khai, minh bạch trong hoạt động xét xử, thực hiện quyền tư pháp của tòa án được đa phần các nước tiến hành thường xuyên, có ý nghĩa tích cực đối với việc thực hiện chức năng xét xử của tòa án.
- Cách tiếp cận thực nghiệm: Hướng tới giải quyết các vấn đề lý luận và thực tiễn là cơ sở cho việc hình thành cơ chế và tiêu chí đánh giá tính công khai, minh bạch trong hoạt động xét xử, thực hiện quyền tư pháp của tòa án. Cách tiếp cận này, ngoài các vấn đề lý luận về tính công khai, minh bạch của hoạt hoạt động xét xử, thực hiện quyền tư pháp,... còn cũng được sử dụng để quan sát thực trạng cơ chế đánh giá tính công khai, minh bạch trong hoạt động xét xử, thực hiện quyền tư pháp của tòa án, thông qua đó đưa ra những nhận xét đầy đủ, khách quan về hoạt động đánh giá tính công khai, minh bạch trong hoạt động xét xử, thực hiện quyền tư pháp của tòa án.

\section{Minh bạch tư pháp ở một số nước trên thế giới}

Trên cơ khảo cứu minh bạch tư pháp ở Anh, Hoa Kỳ, Trung Quốc [22] cho thấy các quốc gia đều nỗ lực thúc đẩy minh bạch tư pháp và thể hiện các đặc điểm sau:

Thứ nhất, việc thúc đẩy minh bạch tư pháp gắn liền với các quy định về công bố thông tin của chính phủ. Luật công bố thông tin của chính phủ được xây dựng không chỉ là nhu cầu của quốc gia trong việc xây dựng nhà nước dân chủ và tạo điều kiện cho người dân tham gia xây dựng chính sách công mà còn là nhu cầu chống tham nhũng cũng như nhu cầu hiện đại hoá và phát triển thông tin. Có thể nói, sự tiến bộ của luật công bố thông tin không chỉ cải thiện tính minh bạch của các cơ quan chính phủ mà còn thể hiện nhu cầu công khai, minh bạch, là nền tảng và thúc đẩy việc công khai thông tin của các Toà án và các cơ quan công quyền khác.

Thứ hai, các quốc gia đều quan tâm đến việc xây dựng hệ thống, thiết lập các quy tắc và quy định, làm rõ trách nhiệm của các Toà án trong việc thúc đẩy minh bạch tư pháp. Thúc đẩy minh bạch tư pháp là một phương tiện quan trọng để bảo vệ các bên và quyền của công chúng được biết và giám sát các hoạt động tư pháp. Để đảm bảo rằng cơ quan tư pháp công bố thông tin một cách kịp thời, toàn diện chính 
xác và hiệu quả, trách nhiệm của các cơ quan tư pháp phải được làm rõ, chẳng hạn như những gì Toà án các cấp phải công bố, tiết lộ ở đâu, khi nào cho ai,... Trong quá trình thúc đẩy minh bạch tư pháp, các quốc gia và khu vực đã rất coi trọng việc xây dựng hệ thống pháp luật, nhấn mạnh tăng cường pháp luật về tính công khai của tư pháp, tập trung vào các yêu cầu cụ thể về tính công khai của tư pháp vào việc thực hiện các nhiệm vụ khác nhau của Toà án.

Thứ ba, coi trọng ứng dụng công nghệ thông tin và internet để tăng cường minh bạch tư pháp. Việc phổ cập, ứng dụng công nghệ thông tin và internet là dấu hiệu quan trọng cho sự xuất hiện của xã hội thông tin, công nghệ thông tin không chỉ ảnh hưởng đến phương thức trao đổi thông tin, phương thức sản xuất và đời sống của người dân mà còn ảnh hưởng đến hoạt động của chính phủ, thúc đẩy sự phát triển của chính phủ điện tử, thúc đẩy mạnh mẽ sự minh bạch của tư pháp. Với việc sử dụng rộng rãi công nghệ thông tin, internet trong các hoạt động của chính phủ, các cơ quan chính phủ của các quốc gia đã liên tiếp khởi động các dự án internet của chính phủ, sử dụng internet để thực hiện công bố thông tin, sử dụng các dịch vụ trực tuyến và tăng cường tương tác giữa chính phủ và công chúng. Làn sóng này cũng ảnh hưởng không nhỏ tới ngành tư pháp. Toà án của các quốc gia cũng đã và đang tham gia làn sóng chính phủ điện tử, thúc đẩy các hoạt động tư pháp trực tuyến. Sau khi internet ra đời như một phương tiện, sự minh bạch tư pháp đã có một nền tảng công bố thông tin hiệu quả, có hệ thống, hiệu quả và toàn diện hơn. Các cơ quan tư pháp có thể công khai một lượng lớn thông tin tư pháp cho một số lượng lớn người dân một cách kịp thời, nhanh chóng, thuận tiện, tiết kiệm thời gian và tiền bạc.

Minh bạch tư pháp là yếu tố không thể thiếu trong công cuộc xây dựng một nền tư pháp văn minh, hiện đại mà các quốc gia Anh, Hoa Kỳ, Trung Quốc đều muốn hướng tới. Mặc dù còn nhiều sự khác biệt nhưng đều có chung mục đích, các quốc gia trên đều không ngừng cải thiện nền tảng minh bạch tư pháp, đổi mới các biện pháp minh bạch tư pháp, nâng cao chất lượng và hiệu quả của công khai minh bạch, đáp ứng nhu cầu tư pháp đa dạng của công chúng và thúc đẩy hiệu quả công bằng tư pháp, góp phần tạo ra uy tín tư pháp. Chung quy lại, các quốc gia dù mang thể chế chính trị, hệ thống pháp luật nào cũng được miễn mang lại lợi ích cho người dân.

\section{Thực trạng, thực tiễn đánh giá tính công khai, minh bạch trong hoạt động xét xử, thực hiện quyền tư pháp của tòa án ở Việt Nam}

\subsection{Chính sách và pháp luật về đánh giá tính công khai, minh bach trong hoạt động xét xư, thực hiện quyền tư pháp của tòa án ở Việt Nam}

Trên cơ sở Nghị quyết số 49-NQ/TW về Chiến lược cải cách tư pháp đến năm 2020 [i) Mục tiêu] Hiến pháp năm 2013 lần đầu tiên xác định tòa án có vai trò trung tâm trong thực hiện quyền tư pháp (Điều 102) đã phản ánh nhu cầu công khai, minh bạch trong hoạt động xét xử của tòa án Việt Nam. Điều 31 Hiến pháp năm 2013 quy định: "ii) Người bị buộc tội phải được Tòa án xét xử kịp thời trong thời hạn luật định, công bằng, công khai. Trường hợp xét xử kín theo quy định của luật thì việc tuyên án phải được công khai.". Trên cơ sở Hiến pháp Luật Tổ chức Tòa án năm 2014 (Điều 11), Luật Tổ chức điều tra hình sự năm 2015 (Điều 13) quy định việc công khai, minh bạch trong hoạt động tư pháp.

Bộ luật Tố tụng dân sự năm 2015 và Bộ luật Tố tụng hình sự năm 2015 quy định thủ tục giải quyết vụ án hướng tới bảo đảm tính công khai, minh bạch trong hoạt động giải quyết vụ án đồng thời quy định trách nhiệm giải trình hoạt động tư pháp của các cơ quan tư pháp. Các nguyên tắc Tòa án xét xử kịp thời, công bằng, công khai (Điều 15 BLTTHDS năm 2015; Điều 25 BLTTHS năm 2015); Nguyên tắc bảo đảm tranh tụng trong xét xử (Điều 26 BLTHS năm 2015),... được quy định bảo đảm cho hoạt động tư pháp được tiến hành công khai, minh bạch và khẳng định trách nhiệm giải trình của các cơ quan tư pháp.

Thủ tục tố tụng hiện hành ở mức độ nào đó đã ấn định tính công khai, minh bạch và trách 
nhiệm giải trình của hệ thống tư pháp Việt Nam, chẳng hạn các phiên xử được tổ chức công khai ngoại trừ trường hợp liên quan đến danh dự cá nhân hoặc thuần phong mỹ tục, hoặc các bên liên quan được quyền xuất trình chứng cứ và tranh luận công khai tại phiên xử.

Như vậy, Việt Nam đã có khá nhiều chính sách, quy định pháp luật quy định những yêu cầu và nguyên tắc công khai, minh bạch trong hoạt động xét xử của Tòa án. Những quy định này tập trung trên các khía cạnh sau: i) Công khai, minh bạch trong hoạt động tổ chức xét xử (chuẩn bị xét xử, xét xử tại phiên tòa); ii) Công khai, minh bạch trong kết quả của hoạt động xét xử; iii) Công khai, minh bạch trong kiểm tra, giám đốc việc xét xử; và quyền được tiếp cận các thông tin về hoạt động xét xử của tòa án.

Tương ứng với các yêu cầu công khai, minh bạch, Việt Nam cũng có các cơ chế để kiểm tra, đánh giá kết quả thực hiện. Mặc dù các cơ chế đánh giá không được quy định tập trung, thành hệ thống trong một văn bản và cũng chưa được luật hóa rõ ràng với tư cách là các tiêu chí đánh giá tính công khai, minh bạch của Tòa án nhưng thông qua các quy định pháp luật về yêu cầu công khai, minh bạch trong hoạt động xét xử có thể xác định thành các cơ chế đánh giá nhằm "đo lường" mức độ công khai, minh bạch trong hoạt động xét xử, thực hiện quyền tư pháp của Tòa án ở Việt Nam hiện nay.

\subsection{Thực tiễn đánh giá tính công khai, minh bach trong hoạt động xét xủ, thưc hiện quyền tu pháp của tòa án ở Việt Nam}

Mặc dù chưa hình thành cơ chế nhưng thực tiễn đã có một số hoạt động đánh giá tính công khai, minh bạch trong hoạt động xét xử, thực hiện quyền tư pháp của tòa án ở Việt Nam, cụ thể như sau: Thứ nhất, Tòa án thường xuyên kiểm tra việc bố trí phòng xử án đã thể hiện được sự trang nghiêm, an toàn, bảo đảm sự bình đẳng giữa người thực hành quyền công tố và luật sư, người bào chữa khác, khi tham gia phiên tòa, bảo đảm tính công khai của hoạt động xét xử và uốn nắn những sai sót, lệch lạc [24 - 26]; Thứ hai, tăng cường kiểm tra tính công khai, minh bạch của hoạt động xét xử thông qua việc triển khai các biện pháp: Đẩy mạnh ứng dụng khoa học - công nghệ, nhất là công nghệ thông tin; Xây dựng hệ thống tố tụng điện tử thông minh - hệ thống cốt lõi để xây dựng Tòa án điện tử, bảo đảm hoạt động của Tòa án được công khai, người dân dễ tiếp cận và giám sát, các vụ việc phải được thụ lý và giải quyết nhanh chóng; Xây dựng hình ảnh Tòa án thân thiện, "gần dân, hiểu dân, giúp dân, học dân"; Gửi, nhận đơn khởi kiện, tài liệu, chứng cứ và cấp, tống đạt, thông báo văn bản tố tụng bằng phương tiện điện tử [27]. Thứ ba, thực hiện việc công khai bản án $[28,29]$, xây dựng và đưa Trang thông tin điện tử Công bố bản án, quyết định của Tòa án vào hoạt động; Thứ tư, kiểm tra, kiểm soát việc giải quyết đơn thư khiếu nại, tố cáo đối với hoạt động xét xử của Tòa án, trong đó có đánh giá về tính công khai, minh bạch trong hoạt động xét xử; Thứ năm, Giám đốc việc xét xử. Thời gian qua, Tòa án nhân dân tối cao đã đề ra nhiều giải pháp có tính đột phá để nâng cao kết quả giải quyết đơn đề nghị giám đốc thẩm, tái thẩm, đã đổi mới việc tiếp nhận và thụ lý đơn đề nghi giám đốc thẩm, tái thẩm, quản lý chặt chẽ sô đơn phải giải quyết, đã giải quyết, chưa giải quyết, đánh giá hoạt động xét xử (trong đó có tính công khai, minh bạch) của Tòa án thông qua công tác giám đốc xét xử của Tòa án cấp trên trong những năm qua được quan tâm. Thứ sáu, đánh giá tính công khai, minh bạch hoạt động xét xử của Quốc hội, Hội đồng nhân dân các cấp thông qua việc xem xét báo cáo công tác của Tòa án nhân dân và hoạt động chất vấn trong các Kỳ họp của Quốc hội, Hội đồng nhân dân các cấp.

\section{Hoàn thiện cơ chế đánh giá tính công khai, minh bạch trong hoạt động xét xử, thực hiện quyền tư pháp của tòa án góp phần cải cách tư pháp ở Việt Nam}

6.1. Nhũng yêu cầu của việc hoàn thiện co chế đánh giá tính công khai, minh bạch trong hoạt động xét xử, thực hiện quyền tư pháp của tòa án

Đánh giá tính công khai, minh bạch trong hoạt động xét xử, thực hiện quyền tư pháp 
của tòa án là tất yếu khách quan trong quá trình xây dựng nhà nước pháp quyền XHCN trong giai đoạn hiện nay, do đó đòi hỏi phải có cơ chế đánh giá khách quan, hiệu quả, phù hợp với điều kiện ở nước ta xuất phát từ những yêu cầu sau:

i) Thực tiễn hoạt động xét xử, thực hiện quyền tư pháp ở nước ta những năm qua cho thấy, bên cạnh một số hoạt động đánh giá của Quốc hội, Hội đồng nhân dân các cấp thông qua việc thực hiện quyền giám sát và chất vân tại các kỳ họp hoặc hoạt động kiểm tra, giám đốc xét xử của tòa án thì cơ chế đánh giá tính công khai, minh bạch trong hoạt động xét xử, thực hiện quyền tư pháp của tòa án chưa hình thành rõ nét. Tính công khai, minh bạch trong hoạt động xét xử, thực hiện quyền tư pháp của tòa án chỉ được đề cập ở một số hoạt động đơn lẻ của tòa án và cơ quan quyền lực, chưa phải là yêu cầu bắt buộc đối với đối với hoạt động của các cơ quan này.

ii) Mặc dù đã có những quy định của pháp luật về trách nhiệm của một số chủ thể đánh giá tính công khai, minh bạch trong hoạt động xét xử, thực hiện quyền tư pháp của tòa án nhưng chưa đầy đủ, nhiều nội dung của cơ chế đánh giá chưa được luật hóa.

iii) Bảo vệ quyền con người, bảo vệ công lý là một trong những mục tiêu quan trọng của tố tụng tư pháp, do vậy cần có cơ chế đánh tính công khai, minh bạch trong hoạt động xét xử, thực hiện quyền tư pháp của tòa án hiệu quả xác định khách quan mức độ bảo vệ quyền con người trong hoạt động tư pháp.

iv) Hội nhập quốc tế là một trong những đòi hỏi tất yếu của quá trình toàn cầu hóa nhằm giúp các quốc gia có thể đạt được sự phát triển, trong đó tư pháp là lĩnh vực quan trọng. Do đó, để phù hợp với thông lệ quốc tế cũng như yêu cầu hội nhập quốc tế của nước ta hiện nay cần xây dựng cơ chế đánh giá tính công khai, minh bạch trong hoạt động xét xử, thực hiện quyền tư pháp của tòa án.

v) Nghị quyết số 49-NQ/TW về chiến lược cải cách tư pháp đến năm 2020 đã đưa ra định hướng xây dựng nền tư pháp trong sạch, vững mạnh, dân chủ, nghiêm minh, bảo vệ công lý, từng bước hiện đại, phục vụ nhân dân, phụng sự
Tổ quốc Việt Nam xã hội chủ nghĩa; hoạt động tư pháp mà trọng tâm là hoạt động xét xử được tiến hành có hiệu quả và hiệu lực cao [1, Mục tiêu] đặt ra yêu cầu cần phải hình thành cơ chế đánh giá tính công khai, minh bạch trong hoạt động xét xử, thực hiện quyền tư pháp của tòa án.

\subsection{Nhũng vấn đề hoàn thiện co chế đánh giá tính công khai, minh bạch trong hoạt động xét xử, thực hiện quyền tư pháp của tòa án}

Những yêu cầu nêu trên cho thấy việc hoàn thiện cơ chế đánh giá tính công khai, minh bạch trong hoạt động xét xử, thực hiện quyền tư pháp của tòa án là cần thiết và hết sức cấp bách trong giai đoạn cải cách tư pháp hiện nay. Việc hoàn thiện cơ chế đánh giá tính công khai, minh bạch trong hoạt động xét xử, thực hiện quyền tư pháp của tòa án cần xuất phát từ yêu cầu cải cách tư pháp, thực tiễn giải quyết vụ án và các điều kiện bảo đảm cho hoạt động đánh giá cũng như kinh nghiệm quốc tế và các kết quả nghiên cứu khoa học trong lĩnh vực này. Do đó, những vấn đề sau đây sẽ được đề cập khi hoàn thiện cơ chế đánh giá tính công khai, minh bạch trong hoạt động xét xử, thực hiện quyền tư pháp của tòa án:

i) Luật hóa việc đánh giá tính công khai, minh bạch trong hoạt động xét xử, thực hiện quyền tư pháp của tòa án. Cần phải quy định rõ trong luật trách nhiệm đánh giá của mỗi tòa án và toàn bộ hệ thống tòa án về tính công khai, minh bạch trong hoạt động xét xử, thực hiện quyền tư pháp của tòa án và kết quả đánh giá này phải được phản ánh trong Báo cáo hằng tháng, quý, Báo cáo thường niên và được công khai để mọi thành phần trong xã hội có thể tiếp cận dễ dàng. Tương tự như vậy, khi Quốc hội, Hội đồng nhân dân các cấp tiển hành giám sát, chất vấn phải có nội dung đánh giá tính công khai, minh bạch trong hoạt động xét xử, thực hiện quyền tư pháp của tòa án.

Ngoài ra, cũng nên quy định để các cơ quan, tổ chức, cá nhân khi có nhu cầu cũng được quyền đánh giá tính công khai, minh bạch trong hoạt động xét xử, thực hiện quyền tư pháp của tòa án. Với cách tiếp cận này, các cơ quan, tổ chức có thể thành lập tổ chức đánh 
giá độc lập về tính công khai, minh bạch trong hoạt động xét xử, thực hiện quyền tư pháp của tòa án.

Cần quy định nguyên tắc đánh giá tính công khai, minh bạch trong hoạt động xét xử, thực hiện quyền tư pháp của tòa án là phương châm, định hướng cho hoạt động đánh giá. Các nguyên tắc đánh giá sau đây được luật hóa: Nguyên tắc khách quan; nguyên tắc toàn diện; nguyên tắc thường xuyên; nguyên tắc giải trình.

Cần quy định kết quả đánh giá tính công khai, minh bạch trong hoạt động xét xử, thực hiện quyền tư pháp của tòa án được xã hội phản biện và tòa án phải có trách nhiệm giải trình, tiếp thu.

ii) Xây dựng quy trình đánh giá khách quan về tính công khai, minh bạch trong hoạt động xét xử, thực hiện quyền tư pháp của tòa án với các nội dung sau:

- Xác định mục tiêu của việc đánh giá tính công khai, minh bạch trong hoạt động xét xử, thực hiện quyền tư pháp của tòa án làm định hướng cho hoạt động đánh giá. Định hướng này phụ thuộc chủ thể đánh giá, tuy nhiên với bất kỳ mục đích gì thì việc xác định mục tiêu đánh giá phải rõ ràng, cụ thể, nêu rõ thời hạn và ý nghĩa của việc đánh giá.

- Xây dựng các căn cứ, tiêu chí (chỉ số) đánh giá tính công khai, minh bạch trong hoạt động xét xử, thực hiện quyền tư pháp của tòa án với một cấu trúc hợp lý phù hợp với mục tiêu đặt ra. Trong cấu trúc đánh giá này sẽ bao gồm các căn cứ là các lĩnh vực thể hiện tính công khai, minh bạch của quy định pháp luật và thực tiễn áp dụng, thực thi nó trong hoạt động xét xử. Trên cơ sở các căn cứ được xác định sẽ có hệ thống các tiêu chí đánh giá nhằm cụ thể hóa thông qua các chỉ số có thể đo lường được mức độ công khai, minh bạch trong hoạt động xét xử, thực hiện quyền tư pháp của tòa án.

Những căn cứ sau cần phải được thiết lập: a) Nhóm căn cứ thứ nhất nhằm đánh giá tính công khai, minh bạch trong hoạt động xét xử, thực hiện quyền tư pháp của tòa án được quy định trong luật ở mức độ nào, sẽ bao gồm: Quy định về nguyên tắc và những bảo đảm giá tính công khai, minh bạch trong hoạt động xét xử, thực hiện quyền tư pháp của tòa án; Quy định về công khai, minh bạch trong thủ tục tố tụng; Quy định về công khai, minh bạch trong giai đoạn chuẩn bị xét xử; Quy định về công khai, minh bạch tại phiên tòa; Quy định về sự tham gia và tiếp cận thông tin đối với hoạt động xét xử của người dân, công luận và xã hội; Quy định về công khai bản án và các dữ liệu của vụ án; Quy định về các điều kiện bảo đảm về công khai, minh bạch trong hoạt động xét xử, thực hiện quyền tư pháp của tòa án...; b) Nhóm căn cứ thứ hai nhằm xác định mức độ công khai, minh bạch trên trên thực tế trong hoạt động xét xử, thực hiện quyền tư pháp của tòa án, bao gồm: Thực hiện qui định về công khai, minh bạch trong các thủ tục tố tụng; Thực hiện qui định về công khai, minh bạch trong giai đoạn chuẩn bị xét xử; Thực hiện quy định về công khai, minh bạch tại phiên tòa; Thực hiện quy định về sự tham gia và tiếp cận thông tin đối với hoạt động xét xử của người dân, công luận và xã hội; Thực hiện quy định về công khai bản án và các dữ liệu của vụ án, ... c) Nhóm căn cứ thứ ba, nhằm xác định mức độ các điều kiện bảo đảm về công khai, minh bạch trong hoạt động xét xử, thực hiện quyền tư pháp của tòa án, đó là: Thể chế; Con người (thẩm phán và cán bộ tòa án); Cơ sở vật chất và phương tiện kỹ thuật,...

Mỗi căn cứ nêu trên cần được cụ thể hóa bằng các tiêu chí (chỉ số) để đánh giá tính công khai, minh bạch trong hoạt động xét xử, thực hiện quyền tư pháp của tòa án. Khi xây dựng, các tiêu chí cần cu thể, có thể so sánh được giữa các chỉ số định tính và định lượng; đồng thời phải hình thành được một bộ các biến số để đánh giá những thay đổi đối với minh bạch tư pháp trong khoảng thời gian nhất định.

- Thu thập nguồn dữ liệu, lựa chọn các phương pháp và kỹ thuật đánh giá: Việc xây dựng các chỉ số đánh giá phải được xây dựng trên cơ sở tính đến các dữ liệu thông tin có sẵn, các dữ liệu có thể thu thập được và chi phí của việc thu thập và phân tích dữ liệu thông tin tiết giảm đến mức thấp nhất có thể. Với cách tiếp cận này thì nguồn dữ liệu thu thập cần hướng tới những dữ liệu sẵn có để giảm thiểu tối đa chi phí, đồng thời phải lựa chọn các phương 
pháp và biện pháp kỹ thuật hiệu quả, khách quan, phù hợp. Trong mọi trường hợp, dữ liệu thu thập được phải chuyển thành thông tin và kiến thức có thể góp phần nâng cao hiệu quả việc thực hiện chức năng của tòa án. Chất lượng dữ liệu phải luôn luôn được kiểm chứng dù đó là dữ liệu được thu thập từ sổ ghi án bằng giấy, hay đối với các dữ liệu thu thập được từ các hệ thống quản lý án điện tử. Cần có những nỗ lực để đảm bảo rằng việc nhập dữ liệu được đồng bộ, thống nhất ở mức cao nhất nhằm tránh làm cho việc so sánh giữa các tòa án bị sai lệch khi thu thập thông tin bằng các tiêu chí khác nhau. Trong nỗ lực này việc xây dựng một cuốn từ điển dữ liệu cũng như sự tham gia của các cơ quan thanh tra trong việc kiểm soát chất lượng dữ liệu là cần thiết [1, tr.102].

iii) Công bố kết quả đánh giá tính công khai, minh bạch trong hoạt động xét xử, thực hiện quyền tư pháp của tòa án. Công bố kết quả là công đoạn cuối của bất kỳ hoạt động đánh giá nào và đánh giá tính công khai, minh bạch trong hoạt động xét xử, thực hiện quyền tư pháp của tòa án không phải ngoại lệ. Tuy nhiên, việc công bố kết quả đánh giá tính công khai, minh bạch trong hoạt động xét xử, thực hiện quyền tư pháp của tòa án cần ở phạm rộng đối với toàn xã hội, không chỉ nên bó hẹp trong nội bộ tòa án và các cơ quan nhà nước có liên quan. Đồng thời, tòa án cũng phải có trách nhiệm giải trình đối với kết quả đánh giá khi có phản biện xã hội về việc thực hiện tính công khai, minh bạch trong hoạt động xét xử, thực hiện quyền tư pháp của tòa án.

Một cơ chế đánh giá tính công khai, minh bạch trong hoạt động xét xử, thực hiện quyền tư pháp của tòa án khách quan, hiệu quả sẽ góp phần quan trọng vào quá trình cải cách tư pháp, bảo vệ quyền con người, bảo vệ công lý nên đòi phải được hoàn thiện theo hướng khách quan, khoa học.

\section{Tài liệu tham khảo}

[1] Bộ Chính trị (2005), Nghị quyết số 49-NQ/TW về chiến lược cải cách tư pháp đến năm 2020 , Link tham khảo:
https://moj.gov.vn/qt/clqhkh/Pages/chien-luocquy-hoach-ke-hoach.aspx?ItemID=11\&CateID=1 (truy cập lần cuối: 22/8/2020).

[2] Liên Hợp quốc, Hướng dẫn tăng cường năng lực và liêm chính tư pháp (bản tiếng Việt), New York, 2011.

[3] H. Harty, D. Fish, Impoving Productivity and Productivity Measurement in Local Government, The Urban Institute: Washington, 1971.

[4] Ross J. Burkhead, Productivity in the Local Government Sector, Lexington Books, 1974.

[5] J. Matzer (Chủ biên), Productivity Impovement Technique, ISMA: Washington, 1986.

[6] E.A. Morley, Partitioners Guide to Public Sector Productivity improvement, Van Nostrand Reinhold: New York, 1986.

[7] J. F. Wholey, Evaluation and Effective Public Management, Little: Boston, 1983.

[8] Kin Sung-ho, The Constitutional Soul of Korea's democracy, Political change in Korea (Insight into Korea Series Vol.3), The Korea Herald và Hiệp hội Khoa học chính trị biên tập, NXB Jimoondang, Seoul, 2008.

[9] Cha Dong-wook, "The Constitutional Court: Political or Legal", Political change in Korea (Insight into Korea Series Vol.3), The Korea Herald và Hiệp hội Khoa học chính trị biên tập, NXB Jimoondang, 2008.

[10] Wen-chen Chang, "East Asian Foundation for Constitutionalism: Three Models Reconstructed", National Taiwan University Law Review, 2009 Vol. 3:2, pp. 111-141.

[11] Wen-chen Chang, The Emergence of East Asian Constitutionalism: Features in Comparison, American Journal of Comparative Law, 2011, Vol. 59.

[12] Wen-Chen Chang, Strategic judicial responses in politically charged cases: East Asian experiences, I.CON (2010), Vol. 8, No. 4, pp. 885-910.

[13] Võ Khánh Vinh, Về quyền tư pháp và chế độ tư pháp ở Việt Nam, Tạp chí Tòa án Nhân dân (điện tử): https://tapchitoaan.vn/bai-viet/phap-luat/vequyen-tu-phap-va-che-do-tu-phap-o-nuoc-ta (truy cập lần cuối: 10/7/2020).

[14] Bryan. Garner, ed., Black's Law Dictionary, $9^{\text {th }}$ ed, 2009.

[15] Các nguyên tắc Bangalore về ứng xử tư pháp, Giá trị 3: Liêm chính, Application 3.2.

[16] Liên Hợp quốc (1948), Tuyên bố toàn thế giới về nhân quyền, Bản tiếng Việt tại: https://thuvienphapluat.vn/van-ban/quyen-dan- 
su/Tuyen-ngon-quoc-te-nhan-quyen-194865774.aspx (truy cập lần cuối: 22/5/2020).

[17] Liên Hợp quốc, Công ước Quốc tế về các quyền dân sự và chính trị, 1966. Bản tiếng Việt tại: https://thuvienphapluat.vn/van-ban/linh-vuckhac/Cong-uoc-quoc-te-ve-quyen-dan-su-vachinh-tri-270274.aspx (truy cập lần cuối: 22/5/2020).

[18] Council of Europe, Convention for the Protection of Human Rights and Fundamental Freedoms (ECHR), 1950, link:

https://www.echr.coe.int/Documents/Convention ENG.pdf (on: 24/5/2020).

[19] Inter-American (1969), American Convention on Human Rights, link:

https://webcache.googleusercontent.com/search? q=cache:uqt2rVUhYmQJ:https://www.cidh.oas.o $\mathrm{rg} / \mathrm{basicos} /$ english/basic3.american\%2520convent ion.htm $+\& \mathrm{~cd}=1 \& \mathrm{hl}=\mathrm{vi} \& \mathrm{ct}=\mathrm{clnk} \& \mathrm{gl}=\mathrm{vn} \quad(\mathrm{on}:$ 24/5/2020).

[20] Liên Hợp quốc, Công ước của Liên Hợp Quốc về chống tham nhũng, 2003. Bản tiếng Việt tại: https://thuvienphapluat.vn/van-ban/bo-may-hanhchinh/Cong-uoc-chong-tham-nhung-cua-LienHop-quoc-09-12-2003-94971.aspx (truy cập lần cuối: 22/02/2020).

[21] Liên Hợp quốc, Hướng dẫn tăng cường năng lực và liêm chính tư pháp, New York, 2011. Bản tiếng Việt tại:

https://www.unodc.org/documents/southeastasiaan dpacific/2014/04/judicial-vietnam/UNODC_-
Judicial_Integrtiy_Vietnamese.pdf (truy cập lần cuối: $22 / 02 / 2020)$.

[22] Nguyễn Ngọc Chí, Nguyễn Ngọc Mai, Minh bạch tư pháp trong lĩnh vực hình sự ở một số quốc gia và kinh nghiệm cho Việt Nam, Tạp chí Khoa học ĐHQG Hà Nội - Chuyên san Luật học, 2020, tập 36, Số 3, tr.16 - 28.

[23] Hiến pháp Cộng hòa XHCN Việt Nam năm 2013.

[24] Thông tư số 01/2017/TT-TANDTC ngày 28/7/2017 Quy định về phòng xử án.

[25] Thông tư số 02/2017/TT-TANDTC ngày 28/7/2017 Ban hành Quy chế tổ chức phiên toà.

[26] Quyết định số 1738/QĐ-TANDTC ngày 23/11/2017 của Chánh án Tòa án nhân dân tối cao về Ban hành Quy chế cấp phát, sử dụng và quản lý trang phục, giấy chứng minh thẩm phán, giấy chứng minh hội thẩm, giấy chứng nhận chức danh tư pháp, giấy chứng nhận tòa án nhân dân.

[27] Nghị quyết số 04/2016/NQ-HĐTP của Hội đồng Thẩm phán Tòa án nhân dân Tối cao về Hướng dẫn thi hành một số quy định của Bộ luật Tố tụng Dân sự số 92/2015/QH13, Luật Tố tụng Hành chính số 93/2015/QH13 về gửi, nhận đơn khởi kiện, tài liệu, chứng cứ và cấp, tống đạt, thông báo văn bản tố tụng bằng phương tiện điện tử.

[28] Nghị quyết số 03/2017/NQ-HĐTP của Hội đồng Thẩm phán Tòa án nhân dân Tối cao về việc Công bố bản án, quyết định trên Cổng thông tin điện tử của Tòa án.

[29] Công văn số 144/TANDTC-PC ngày 04/7/2017 của Tòa án nhân dân tối cao về việc thi hành Nghị quyết số 03/2017/NQ-HĐTP. 